\title{
Medical technology as the object of ethics
}

Years before World War II, a new technology boomed in more developed countries, a technology that stood out from anything seen in the past. We could imagine it was the result of human evolution, as it had always been, but subsequent results proved it was not. As technology developed, there was a growing concern on its use or application, the confirmation of which being the direct connection between World War II and the well-known, unprecedented genocidal events. Intellectual and scientific icons spoke out to warn on the risks that lurked around humankind. There is a brief but convincing phrase by Albert Einstein that reflects the reality of those times: "It has become appallingly obvious that our technology has exceeded our humanity."

It is worth noting that changes resulting from the so-called modern technology refer not only to the creation of new tools, instruments, equipment, etc., but also to the essential modifications of its dynamics compared to other developments undertaken by men throughout history. It is not necessary to go back hundreds of years in time, we could just look at the events that took place between the $19^{\text {th }}$ century and the first decades of the $20^{\text {th }}$ century. Even in the dawn of the industrial revolution, back then the development of tools and equipment was consistent and balanced in terms of objectives and results obtained. If tools and equipment worked, they remained in use for many years and were replaced only when they stopped working or a new, more adequate technique emerged.

By contrast, many substantial changes were subsequently observed in the dynamics of technology, which were certainly not promising. Among others, a few can be mentioned as follows: each new step does not lead to a balance point, if it is successful, it multiplies infinitely so; new technological "advances" are disseminated and publicized extremely fast, even before their actual use can be adequately assessed; the relationship between means and ends does not go in a oneway linear direction, it is rather like a loop: the development of new techniques results in new objectives that, in turn, bring about the modification of the previous technology, even if differences are minimum. I do not need to point out that such dynamics are mainly based on profit and have led to an era of ongoing heavy consumption still present today in several aspects of everyday life. Just to mention one example, it is now practically mandatory to get the latest mobile phone, although we do not actually use them as telephones, and the differences from the previous version only have to do with layout, not with features.

Technological changes took place a bit later in the field of medicine, most notably in the 1950s, with the development of a new technique that progressively "invaded" medical practice. In the beginning, the process was slow, and this allowed for an adequate assessment of the effectiveness of new equipment and techniques, accompanied by a careful and moderate use. Then the process became relentlessly more dramatic and dazzling. Along such development, major benefits in health care were observed, mainly in terms of diagnostic methods. However, as changes started to occur at a faster and more overwhelming pace, new dilemmas challenged several of the ethical principles of medicine and had a negative impact on medical practice.

As long as said incessant process continues to steadily produce more and newer technologies that continue being profitable, it will not be easy to modify this dynamics which undoubtedly will result in all sorts of potential damages and also to the growing commodization of medicine, which is morally reprehensible.

Likewise, this attitude causes an exorbitant increase in health care costs, making it less sustainable and less affordable, leading to greater inequity and different kind of problems.

It is therefore necessary to take a look at these aspects from a different perspective, even briefly, and to discuss why modern technology has become a matter of philosophy and its "disciple" discipline: ethics. I would like to describe this concept by quoting German philosopher Hans Jonas, who devoted most of his work to study the principle of responsibility and the influence of technology on humanity, including medical practice, reflected in his German book Technik, Medizin und Ethik. Jonas stated: "Given that today technique is part of everything related to the human race: life and death, thinking and feeling, action and suffering, environment and things, desire and destination, present and future, i.e., given that it has become a central and pressing problem on all human existence on Earth, it has become a matter of philosophy, and a philosophy 
of technology needs to emerge." In addition, he made specific considerations regarding ethics: "Ethics has a saying in matters related to technique simply because technology is part of the exercise of human power, namely a form of action, and all human actions or conducts are subject to moral assessment."

To a considerable extent, these concepts allow us to reflect on the use of technology in medical practice and to verify whether we respect ethical principles of medicine and are aware of the power conferred by technology. These reflections might help us find out why us, as doctors, have slowly but increasingly shifted towards science and away from the art of our profession, which encompasses humanism and allows us, as human beings, to approach other human beings, who are our fellow men. The pendulum of medicine tilts towards science and technology and is at risk of leaving altruism aside, a behavior typical and essential of medical practice, an aspect that should be the basis for our behavior and actions when we deal with our patients. An adequate clinical judgment, based on knowledge, intuition and other attributes, together with assistance, understanding, comfort, are all supported by listening and talking to patients, and are part of a different technology, one that is perceived as the language of science and art.

It is well known that the best doctor is not the one who knows more, but the one who has a sound scientific knowledge harmoniously balanced with the practice of art, and this is the only way a doctor can become aware of the history of his/her patients, their thoughts, feelings and aches through empathy and sensitivity in order to know what their actual needs are.

In addition, facing the overwhelming development of technology, we should be more and more cautious of its use, especially if it starts out as promising and successful. An example would be the use of computed tomography (CT) in children, which for many years has been unnecessarily used for unjustifiable situations; and this has become almost a routine. Unfortunately, recent publications have pointed out the increased risk of cancer in children excessively exposed to $\mathrm{x}$-rays through $\mathrm{CT}$ and advise that guidelines on when to order a CT should be strictly followed. Thousands of children have certainly been unfairly affected by such irresponsible conduct.

The abuse of ancillary diagnostic techniques is one of the evils of modern medicine. It is very common that doctors spend little or no time on consultation leading to a defensive medicine, where so as not to "miss" anything, we end up ordering tests and exams that would not be necessary if adequate care was provided. This trend to be submitted to technology, threatens the image of doctors, who instead of using it properly, turn into technicians who do not understand that medical practice goes beyond scientific boundaries.

We should bear in mind that technology "is not a miraculous elixir" and that its effects might be harmful. It is therefore necessary that we all become aware of the extent of modern technology, although this is an aspect hardly considered in our profession.

Be have become disproportionately dependent on technology, taking into account only our best interests, whether financial or spurious, instead of considering patients' real interests, and this makes us behave and act in a morally reprehensible manner.

The respect to the ethical principles of our profession is unavoidable because it maintains the essential aims of medicine that we, as doctors, should comply with; and also because it is a balm to our spirit, the one that allows us to practice medicine with humility and pride.

José M. Ceriani Cernadas Editor

http:/ /dx.doi.org/10.5546/aap.2014.eng.298 